mổ lại. Thời gian hậu phẫu trung bình chung trong nghiên cứu của chúng tôi là 10.28 ngày. Kết quả này tương tự với tác giả Sang Eun Nam (2013). Kết quả của chúng tôi cho thấy số lượng hạch nạo vét được thấp hơn so với các tác giả nước ngoài. Như theo Jin Tung Liang (2008) sô hạch vét được trung bình là 14.4. Kết quả trên có thể giải thích do trong nghiên cứu của chúng tôi có một số bệnh nhân không được nạo vét hạch điển hình như bệnh nhân giai đoạn IV, bệnh nhân tắc ruột, già yếu bệnh kèm theo nặng không cho phép kéo dài cuộc mổ, đồng thời các tác giả nước ngoài có phương tiện làm tiêu mõ mạc treo để thu thập hạch dễ hơn.

\section{KẾT LUÂN}

Phẫu thuật là phương pháp điều trị chính trong ung thư đại trực tràng nói chung. Phẫu thuật nội soi cho thây hiệu quả phẫu thuật cũng như độ an toàn tương đương mổ mở trong khi cải thiển chất lượng cuộc sống và giảm nguy cơ một số biến chứng sau mổ nên cần được áp dụng rộng rãi cho bệnh nhân UTĐT Sigma.

TÀl LIẸU THAM KHẢO
1. SEER (2014), SEER stat Fact Sheets: Colon and Rectum.

2. Nguyễn Văn Lê (2008), "Đánh giá kết quả phẫu thuật nội soi điểu trị ung thư đại tràng tại bệnh viện Việt Đức từ 2003-2008", tr. 51.

3. A. I. Ṕhipps, A. T. Chan, S. Ogino. Anatomic subsite of primary colorectal cancer and subsequent risk and distribution of second cancers. Cancer2013;119(17):3140-3147.

4. C. M. Wray, A. Ziogas, M. W. Hinojosa, et al. Tumor subsite location within the colon is prognostic for survival after colon cancer diagnosis. Dis Colon Rectum 2009;52(8):1359-1366.

5. Nguyễn Xuân Hùng (2002), Kết quả điều trị ung thư đại tràng tại bệnh viện Việt Đức trong 5 năm (1994-1998), Tạp chí y học thực hành, 11, 15-17.

6. Trịnh Hồng Sớn (1995), Nhânn xét về chẩn đoán và điêuu trị 359 trương hợp ung thư đại tràng được mố tai bệnh viên Viêt Đức trong 8 năm(19861993), Tạp chí y học thực hành, 3, 25-27.

7. Chu Văn Đức (2010), Nghiên cứu đă̆c điểm lâm sàng, cận lâm sàng của ung thư đại tràng, Tạp chí y học thực hành, 5(715), 20-25.

8. Nguyến Văn Xuyên (2010) Kết quả điều trị ung thư đại tràng Sigma bằng phâuu thuật triệt để qua 68 trường hợp tai Bệnh viện 103, Tạp chí y dược học quân sự, 7(32), 102-108.

9. K. M. Lin, 'D. M. Ota.Laparoscopic colectomy for cancer: an oncologic feasible option.Surg Oncol 2000;9(3):127-34.

\title{
NGHIÊN CỨU BƯỚC ĐẦU VỀ CAGPAI, OIPA, DUPA CỦA HELICOBACTER PYLORI Ở BỆNH NHÂN LOÉT TÁ TRÀNG TẠI VIỆT NAM
}

\author{
Vũ Văn Khiên', Đoàn Vũ Nam², Nguyễn Quang Duật ${ }^{2}$, \\ Phạm Hồng Khánh ${ }^{2}$, Trần Thị Huyền Trang ${ }^{1}$
}

\section{TÓM TẮT}

Đăt vấn đề: Từ năm 1994, WHO đã xếp H.pylori nằm trong nhóm I gây UTDD. Tuy nhiên, khả năng gây bênh của $H$. pylori phụ thuộc vào yếu tố độc lực của nó. Đề tài nghiên cứu về tỷ lệ cagPAI, oipA, dupA ở bệnh nhân loét tá tràng tại Việt Nam. Đối tượng và phương pháp: 43 bệnh nhân loét tá tràng được chẩn đoán xác định trên nội soi và mô bênh học. CagPAI, oipA, dupA được thực hiện bằng kỹ thuật PCR. Kết quả: Tuổi hay gặp (31-59 tuổi): 60,5\%. Tỷ lệ nam/nữ: 1,5. Các triệu chứng hay gặp trong loét tá tràng gồm: Đau thượng vị, ợ hơi và ợ chua. Số bệnh nhân có 01 ổ loét: $88,4 \%$. Tỷ lê cagPAI, oipA, dupA dương tính ở bệnh nhân loét tá tràng chiếm tỳ lệ tương ứng: $62,8 \%, 9,3 \%, 65,1 \%$. Số bênh nhân có 2 gen kết hợp (cagPAI + dupA) là: 19/34 (55,9\%).

\footnotetext{
${ }^{1}$ Bệnh viện TWQD 108

2Bệnh viện 103 -Học viện Quân Y

Chịu trách nhiệm chính: Vũ Văn Khiên

Email: vuvankhien108@yahoo.com.vn

Ngày nhận bài: 7.6.2021

Ngày phản biên khoa hoc: 23.7.2021

Ngày duyệt bài: 6.8.2021
}

Kết luân: Gen oipA của $H$. pylori là yếu tố nguy cơ cao gây loét tá tràng tại Việt Nam. Cần nghiên cứu trên số lượng nhiêu hơn

Tư khóa: Helicobacter pylori, loét tá tràng, ung thư dạ dày, viêm dạ dày mạn.

\section{SUMMARY \\ INITIAL STUDY ON CAGPAI, OIPA, DUPA OF HELICOBACTER PYLORI IN DUODENAL ULCER PATIENTS IN VIETNAM}

Introduction: Since 1994, WHO has classified H.pylori in group I causing gastric cancer. However, the pathogenicity of $\mathrm{H}$. pylori is highly dependent on its virulence factor. Research topic on the rate of cagPAI, oipA, dupA in duodenal ulcer patients in Vietnam. Patients and mehods: 43 patients with duodenal ulcer were confirmed on endoscopy and histopathology. CagPAI, oipA, dupA were performed by PCR. Results: Common age (31-59 years old): $60.5 \%$. Male/Female ratio: 1.5 . Common symptoms of duodenal ulcer include: epigastric pain, belching and heartburn. Number of patients with 01 ulcer: $88.4 \%$. The rate of positive cagPAI, oipA, dupA in duodenal ulcer patients were $62.8 \%, 9.3 \%, 65.1 \%$, respectively. Number of patients with 2 combined 
genes (cagPAI + dupA) were 19/34 (55.9\%). Conclusion: The oipA gene of $\mathrm{H}$. pylori is a high risk factor for duodenal ulcer in Vietnam. Need to study on more quantity

Keywords: Helicobacter pylori, duodenal ulcer, gastric cancer, chronic gastritis.

\section{I. ĐĂT VẤN ĐỀ}

Bệnh loét dạ dày tá tràng (PUD) là kết quả của sự mất cân bằng giữa lượng acid-pepsin và các yểu tố bảo vệ niêm mạc dạ dày. Hàng năm, có khoảng 4 triệu người bị mắc bệnh loét da dày-tá tràng. Tập hợp 7 nghiên cứu từ các nước phát triển cho biết nguy cơ mắc loét dạ dày tá tràng hằng năm từ $0,10 \%-0,19 \%$ khi được khám bởi các bác sỹ chuyên khoa tiêu hóa và $0,03 \%$ $0,17 \%$ khi được thống kê từ các bệnh viện. Loét tá tràng có nguy cơ cao gây chảy máu tiêu hóa và thủng tạng rồng.

Từ năm 1994, tổ chức y tế giới (WHO) đã xếp Helicobacter pylori $(\mathrm{H}$. pylori) nằm trong nhóm I gây UTDD và cũng là tác nhân chính gây viêm dạ dày mạn, loét dạ dày-tá tràng. Tuy nhiên, khả năng gây bệnh của $H$. pylori phụ thuộc rất nhiều vào yểu tố độc lực (virulence factors) của chúng. Yễu tố độc lực cagA (cytotoxin associated gene A) và vacA (vacuolating cytocin $A$ ) đã được nghiên cứu khá rộng rãi trong UTDD và các bệnh lý dạ dày khác. Tuy nhiên, ngoài 2 gen cagA và vacA thì còn có khá nhiêu các gen khác cũng được đề cập đễn. Gần đây, có nhiêu nghiên cứu đề cập đển các gen khác như cagPAI (cag pathogenicity island), oipA (outer inflammatory protein) và dupA (duodenal ulcer promoting gen) ở bệnh nhân có bệnh lý dạ dày-tá tràng [1]. Năm 2010, Nguyễn Lâm Tùng và cs cũng đã nghiên cứu các gen này chỉ trên các đối tượng là bệnh nhân bị viêm dạ dày mạn. Đề tài nghiên cứu tìm hiểu về tỷ lệ các gen: cagPAI, oipA, dupA ở bệnh nhân loét tá tràng tại Việt Nam.

\section{II. ĐỐI TƯỢNG VÀ PHƯƠNG PHÁP NGHIÊN CỨU}

1. Đối tượng. Trong thời gian từ $06 / 2019$ đên 03/2020, chúng tôi đã thu thập được 43 bệnh nhân loét tá tràng (LTT) đủ tiêu chuẩn được đưa vào nghiên cứu. Bệnh nhân được thu thập tại bệnh viện TWQĐ 108 và bệnh viện 103-
Học viện Quân y.

Tất cả bệnh nhân LTT được chẩn đoán xác định trên nội soi, mô bệnh học và xác định có nhiễm H. pylori (dựa trên urea test và/hoặc mô bệnh học). Tiêu chuẩn loại trừ: Đã cắt dạ dày, dùng kháng sinh hoặc Bismuth (trong vòng 4 tuần), dùng thuốc kháng thụ thể $\mathrm{H}_{2}$ hoặc thuốc ức chế bơm proton trong vòng 2 tuần trước đó.

\section{Phương pháp}

+ Thiết kế nghiên cứu: nghiên cứu cắt ngang

+ Sử dụng máy nội soi EVIS 180 (OlympusNhật Bản).

+ Hình ảnh đại thể loét tá tràng dưa trên kết quả nội soi, bao gồm các thông số: vị trí, số lượng, kích thước, mức độ hoạt động của ổ loét.

+ Mảnh sinh thiết xét nghiệm PCR chẩn đoán H. pylori và các yếu tố độc lực cagPAI, oipA và dupA được cố định trong dung dịch transport medium, bảo quản ở nhiệt độ - 80 độ $\mathrm{C}$. Mẫu bệnh phẩm sau đó được bảo quản trong hộp chuyên dụng, vận chuyển đến khoa Sinh học phân tử - Bệnh viện TWQĐ 108 trong cùng ngày.

+ Kít làm sạch QIAquick (Qiagen). Các cặp mồi, enzym dùng trong phản ứng PCR. Máy đọc kết quả điện di: Chemidoc XRS+ BIO-RAD. Hệ thống điện di mao quản với độ phân giải cao: Microchip electrophoresis system for DNA/RNA analysis MCE $^{\circledR}-202$ MultiNA.

+ Kiểu gen cagPAI được xác định dựa trên sự có mặt của 3 gen: cagA, cagY, cagT.

+ Đối với gen oipA, dupA: Phản ứng PCR được thực hiện bằng cách nâng nhiệt độ của phản ứng lên $94^{\circ} \mathrm{C}$ trong vòng 5 phút, theo sau đó là 35 chu kỳ nhiệt, mỗi chu kỳ bao gồm: Giai đoạn biến tính: $94^{\circ} \mathrm{C}$ trong 30 giây, giai đoạn gắn mồi: $56^{\circ} \mathrm{C}$ trong 30 giây, giai đoạn nối dài: $72^{\circ} \mathrm{C}$ trong 30 giây và cuối cùng là bước kéo dài $72^{\circ} \mathrm{C}$ trong 7 phút.

\section{KẾT QUẢ NGHIÊN CỨU}

Trong thời gian nghiên cứu, chúng tôi mới chỉ thu thập được 43 bệnh nhân LTT đủ tiêu chuẩn đưa vào nghiên cứu. Tất cả các bệnh nhân đều có nhiễm $\mathrm{H}$. pylori và xét nghiệm các gen: cagPAI, oipA và dupA. Sau đây là kểt quả cụ thể:

Bảng 3.1. Đặc điểm tuổi, giới, triệu chứng lâm sàng của $L T$

\begin{tabular}{|c|c|c|c|}
\hline Tuối / giớí & $\mathbf{n ~ ( \% )}$ & Lâm sàng & $\mathbf{n}(\%)$ \\
\hline$\leq 30$ tuối & $9 / 43(20,9)$ & ợ hơi & $37 / 43(86,0)$ \\
\hline $31-59$ tuối & $26 / 43(60,5)$ & ớ chua & $37 / 43(86,0)$ \\
\hline$\geq 60$ tuối & $8 / 43(18,6)$ & Đau thượng vị & $41 / 43(95,3)$ \\
\hline Tuối TB & $44,5 \pm 14,9$ & Nôn & $13 / 43(30,2)$ \\
\hline Tỷ lệ nam/nữ & $26 / 17(1,5)$ & Da và niêm mạc nhợt & $7 / 43(16,3)$ \\
\hline
\end{tabular}

Nhận xét: Tuối hay gặp từ 31-59 tuôi, chiếm: 60,5\%. Tỷ lệ nam/nữ: 1,5. Các triệu chứng hay 
gặp trong LTT gồm: Đau thượng vị, ợ hơi và ợ chua.

Bảng 3.2. Kêt quả về hình ánh nội soí của $L T T$

\begin{tabular}{|c|c|c|c|}
\hline Vị trí ố loét & $\mathbf{n ~ ( \% )}$ & Số lượng ố loét & $\mathbf{n}(\%)$ \\
\hline Măt trước & $33 / 53(76,7)$ & 01 ố loét & $38 / 43(88,4)$ \\
\hline Mặt sau & $7 / 43(16,4)$ & $\geq 2$ ố loét & $5 / 43(11,6)$ \\
\hline Cà hai mặt & $3 / 43(6,9)$ & Tống & $43 / 43(100)$ \\
\hline Tống & $\mathbf{4 3 ( 1 0 0 )}$ & & \\
\hline
\end{tabular}

Nhận xét: O loét HTT gặp nhiêu ở mặt trước: $76,7 \%$, 01 ố loét (88,4\%)

Bảng 3.3. Kết quả về xét nghiệm gen của $L T T$

\begin{tabular}{|c|c|c|c|}
\hline Yếu tố độc lực & $\mathbf{n}(\%)$ & Tố hợp gen & $\mathbf{n}(\%)$ \\
\hline cagPAI $(+)$ & $27 / 43(62,8)$ & cagPAI + oipA + dupA $(\mathrm{n}=2)$ & $2 / 43(4,7)$ \\
\hline oipA $(+)$ & $4 / 43(9,3)$ & cagPAI + oipA $(\mathrm{n}=2)$ & $2 / 43(4,7)$ \\
\hline dupA $(+)$ & $28 / 43(65,1)$ & cagPAI + dupA $(\mathrm{n}=19)$ & $19 / 43(44,2)$ \\
\hline & & oipA + dupA $(\mathrm{n}=4)$ & $4 / 43(9,3)$ \\
\hline & & Không có cả 3 gen $(\mathrm{n}=7)$ & $7 / 43(16,3)$ \\
\hline
\end{tabular}

Nhận xét: Tỷ lệ cagPAI, oipA, dupA dương tính ở bệnh nhân LTT chiếm tỷ lệ tương ứng: $62,8 \%$, $9,3 \%, 65,1 \%$. Tỷ iệ bệnh nhân có 2 gen kết hợp: cagPAI + dupA dương tính chiếm tỷ lệ cao nhất: $19 / 43(44,2 \%)$.

\section{BÀN LUẬN}

4.1. Vai trò của gen cagPAI của H.pylori ở bệnh nhân loét tá tràng. Tiểu đảo bệnh sinh cagA (cag pathogenicity island: cagPAI)) gồm nhiều gen độc lực, đặc biệt là cagA. Sự hiện diện của gen cagA được coi là dấu hiệu cho sự hiện diện của cagPAI. CagA thông qua nhiều cơ chế phức tap đã được chứng minh có vai trò trong bệnh sinh của UTDD. Gen cagA sẽ kích hoạt SHP-2, gây rối loạn phân bào và tương tác với Ecadherin, gây rổi loạn phát triển phôi và cân bằng nội mô và cuối cùng gây UTDD. Gen cagY và cagT mã hóa cho các thành phần của hệ thống bài tiết type IV, có vai trò quan trọng trong vận chuyển cagA vào trong tế bào biểu mô dạ dày. Người nhiếm $\mathrm{H}$. pylori có cagPAI dương tính thường có xu hướng gây tổn thương dạ dày, trong đó có LTT và ung thư dạ dày [2]

Vai trò của gen cagPAI của $\mathrm{H}$. pylori đã được khảng định ở bệnh nhân ung thư dạ dày (UTDD). Tuy nhiên, cũng có nghiên cứu về vai trò của cagPAI ở bệnh nhân viêm dạ dày mạn, loét tá tràng và loét da dày. Tuy nhiên, số lượng nghiên cứu chưa nhiều. Trong nghiên cứu của chúng tôi (trình bày bảng 3.3 ) cho biết tỷ lệ cagPAI dương tính ở bệnh nhân LTT là: $27 / 43$ bênh nhân $(62,8 \%)$. Kết quả này có thấp hơn so với các kết quả nghiên cứu khác. Có thể, do số liệu nghiên cứu (số bệnh nhân loét hành tá tràng) chưa nhiều, nên chưa phản ánh đúng. Cần ngiên cứu trên số lượng lớn hơn.

Năm 2002, Yamaoka Y và cs [2] thực hiện nghiên cứu cagPAI trên 827 bệnh nhân, bao gồm 504 bệnh nhân loét hành tá tràng (chiếm $61 \%$ ) và 323 bệnh nhân viêm dạ dày (chiếm $39 \%$ ). Bệnh nhân được lấy từ 2 vùng: Châu Á (Nhật
+Hàn Quốc, $n=474$ ) và các nước châu Mỹ (Mỹ + Columbia, $n=353$ ). Trong số này, có 295 bệnh nhân loét tá tràng tại châu Á và 209 bệnh nhân loét tá tràng tại chẩu Mỹ. Kết quả nghiên cứu tại châu Á cho biết tỷ lệ cag PAI dương tính ở bệnh nhân loét hành tá tràng là: 288/295 bênh nhân (97,6\%). Kết quả này cao hơn so với tỷ lệ cag PAI ở bệnh nhân loét hành tá tràng là: 196/209 (94\%) tại châu Mỹ

Một nghiên cứu gần đây (2017) về cagPAI trên 240 bệnh nhân người lớn, bao gồm: 120 bệnh nhân khó tiêu chức năng, 50 bệnh nhân loét dạ dày-tá tràng và 70 bệnh nhân UTDD [3]. Kết quả nghiên cuwius phát hiên 122/240 bênh nhân có $\mathrm{H}$. pylori dương tính. Kết quả phân tích về gen cagPAI được thể hiện trên 4 tổ hợp gen: cagA, cag $\mathrm{E}$, cagT và cagM. Kết quả xét nghiệm cho biết tỷ lệ gen cagA, cagE, cagT, cagM dương tính tương ứng ở nhóm khó tiêu chức năng $(73 \%, 83 \%, 76 \%, 60 \%)$, loét da day-tá tràng $(70 \%, 94 \%, 91 \%, 70 \%)$ và UTDD $(75 \%, 95 \%$, $90 \%, 70 \%)$. Nguy cơ loét da dày-tá tràng của cagPAI với 3 gen: cagE, cagT và cagM tương ứng là: 5,$0 ; 4.6$ và 4,1 . Nguy cơ gây loét da dàytá tràng của cagPAI tăng cao hơn (83\%) có ý nghĩa $(p=0,01)$ so với bệnh nhân khó tiêu chức năng. Như vậy, cagPAI cũng là một dấu ấn gây loét dạ dày-tá tràng [3].

4.2. Vai trò của gen oipA của H.pylori ở bệnh nhân loét tá tràng. Protein viêm màng ngoài (outer inflammatory protein: oipA) của $\mathrm{H}$. pylori được phát hiện vào năm 2000 bởi Yamaoka $Y$ và cs [1]. OipA là một trong 5 thành viên protein màng ngoài của vi khuẩn $\mathrm{H}$. pylori và do vậy oipA còn có tên gọi tắt khác là hopH. Vị trí của oipA trên nhiễm sắc thể của $\mathrm{H}$. pylori 
cách cagPAI khoảng 100 kb. Tác động của oipA tới bệnh lý dạ dày phụ thuộc vào trạng thái có hoạt động hoặc không hoạt động "on/off". Một số tác giả khác sử dụng thuật ngữ có mặt hoặc không có mặt "presence/absence". Khi oipA hoạt động sẽ làm tăng nguy cơ loét dạ dày, ung thư dạ dày. Đồng thời nó cũng làm tăng mức độ thâm nhiễm $\mathrm{H}$. pylori trong biểu mô dạ dày, tăng thâm nhiễm bạch cầu đa nhân trung tính ở mức độ nặng [1].

Trong nghiên cứu của chúng tôi trình bày trong bảng 3.3 cho biết oipA $(+)$ chiếm tỷ lệ rất thấp: 4/43 bệnh nhân (9,3\%). Trong một phân tích tổng hợp (meta-analysis) của Liu J và cs [4] trình bày bảng 4.1 cho biết về tỷ lệ oipA (+) theo trạng thái "on/off", kết quả phân tích cho biết tỷ lệ oipA giao động trong khoảng: 82,1-100\%.

Bảng 4.1 Tý lế OipA (+) trạng thái "on/off" ở bệnh nhân LTT [4]

\begin{tabular}{|c|c|}
\hline $\begin{array}{c}\text { Tác giả (năm), } \\
\text { chủng tộc }\end{array}$ & $\begin{array}{c}\text { Tỷ lệ oipA (+) theo trạng } \\
\text { thái "on/off" ở LTi }\end{array}$ \\
\hline $\begin{array}{c}\text { Schmidt HM (2010), } \\
\text { người Trung Quốc }\end{array}$ & $14 / 16(87,5 \%)$ \\
\hline $\begin{array}{c}\text { Yamaoka Y (2006), } \\
\text { người Colombia }\end{array}$ & $36 / 40(90 \%)$ \\
\hline $\begin{array}{c}\text { Yamaoka Y (2006), } \\
\text { người Mỹ }\end{array}$ & $34 / 40(85,0 \%)$ \\
\hline $\begin{array}{c}\text { De Jonge R (2004), } \\
\text { người Đức }\end{array}$ & $23 / 28(82,1 \%)$ \\
\hline $\begin{array}{c}\text { Yamaoka Y (2002), } \\
\text { người Mỹ }\end{array}$ & $37 / 41(90,2 \%)$ \\
\hline $\begin{array}{c}\text { Yamaoka Y (2002), } \\
\text { người Colombia }\end{array}$ & $36 / 40(90 \%)$ \\
\hline $\begin{array}{c}\text { Yamaoka Y (2000), } \\
\text { người Nhật Ban }\end{array}$ & $40 / 40(100 \%)$ \\
\hline
\end{tabular}

Cũng với nghiên cứu của Liu J và cs [4], với trạng thái "present/absence" thì tỷ lệ oipA (+) ở bệnh nhân LTT (bảng 4.2). Kết quả cho biết tỷ lệ oipA ở bệnh nhân LTT trạng thái "present/ absence" giao động từ $30 \%$ đến $92,5 \%$. Tuy nhiên, hạn chế của các nghiên cứu này là số lượng bệnh nhân không nhiều, do vậy chưa đánh giá khách quan về tỷ lệ opiA trong LTT, do vậy, cần phải nghiên cứu trên số lượng lớn hơn.

Bảng $4.2 T \dot{y}$ lệ oipA (t) trang thái "present/absence" ở bệnh nhân LTT [4]

\begin{tabular}{|c|c|}
\hline $\begin{array}{c}\text { Tác giả (năm), } \\
\text { chưng tộc }\end{array}$ & $\begin{array}{c}\text { Tý lệ oipA (+) theo } \\
\text { trạng thái "present/ } \\
\text { absence" ở UTDD }\end{array}$ \\
\hline $\begin{array}{c}\text { Xie J (2010), người } \\
\text { Trung Quốc }\end{array}$ & $6 / 20(30,0 \%)$ \\
\hline $\begin{array}{c}\text { Zhou M (2009)-người } \\
\text { Trung Quốc }\end{array}$ & $37 / 40(92,5 \%)$ \\
\hline
\end{tabular}

Trong một tập hợp nghiên cứu gần (2019) đây của Sterbenc $A$ và cs [5] cho biết tỷ lệ oipA (+) chung cho nhiêu đối tượng nghiên cứu khác nhau (viêm dạ dày mạn, loét dạ dày, loét tá tràng, UTDD, khó tiêu chức năng...) giao động từ 59-100\%. Nghiên cứu của chúng tôi chưa thực hiện trên số lượng lớn ở bệnh nhân. Hy vọng, với số lượng bệnh nhân nhiều hơn, chúng tôi sẽ đánh giá khách quan về tỷ lệ gen oipA $(+)$ ở bệnh nhân loét tá tràng.

4.3. Vai trò của gen dupA của $H$. pylori ở bệnh nhân loét tá tràng. Gen thúc đẩy loét tá tràng (duodenal ulcer promoting gen: dupA) nằm ở vùng plasticity của bộ gen của H. pylori, tương đồng với virB4, một gen mã hóa một protein thành phần của hệ thống tiết týp IV ở vi khuẩn Agrobacterium tumefaciens [6]. Gen dupA bao gồm hai chuỗi liên tục: jhp0917 và jhp0918, như được mô tả trong chủng 399 của $\mathrm{H}$. pylori.

Trong nghiên cứu của chúng tôi trình bày trong bảng 3.3 cho biết tỷ lệ dupA (+) chiếm $28 / 43$ bệnh nhân $(65,1 \%)$. Gen dupA được phát hiện vào năm 2005 bởi Lu $\mathrm{H}$ và cs [6] khi thực hiện nghiên cứu trên 500 mẫu H.pylori thu thập tại châu Á (Nhâat Bản và Hàn Quốc) và ở Colombia. Kết quả nghiên cứu này cho biết dupA có liên quan đến nguy cơ loét hành tá tràng và giảm nguy cơ viêm teo dạ dày và UTDD. Nghiên cứu tiếp theo (2006) được thực hiện tại Trung Quốc bởi Zhang $Z$ và cs [7] trển 360 bệnh nhâ, bao gồm: Loét tá tràng $(\mathrm{n}=101)$, VDDM $(\mathrm{n}=$ $133)$, UTDD $(n=79)$, loét dạ dày $(n=47)$. Kết quả nghiên cứu cho biết tỷ lề dupA (+) ở bệnh nhân: Loét tá tràng, loét da dày, UTDD và VDDM tương ứng là: $45,5 \%, 23,4 \%, 24,1 \%$ và $38,3 \%$. Tỷ lệ dupA (+) ở bệnh nhân loét tá tràng tăng cao hơn có ý nghĩa so với loét da dày và UTDD $(p<0,05)$. Như vây, dupA tăng cao ở bệnh nhân loét tá tràng, nhưng không tăng ở bệnh nhân UTDD và loét dạ dày

Tính đến nay (2005-2019) có tổng cộng có 46 nghiên cứu về dupA trên các đối tượng khác nhau. Tập hợp các nghiên cứu này đã khảng định dupA là một marker gặp nhiều nhất và đặc trưng cho bệnh nhân loét tá tràng, chứ không đặc trưng cho ung thư dạ dày [8]

\section{KẾT LUÂ̂N}

Tỷ lệ cagPAI, oipA, dupA dương tính ở bệnh nhân loét tá tràng tương ứng là: $62,8 \%, 9,3 \%$, $65,1 \%$. Kết quả nghiên cứu ban đầu cho thấy gen dupA thường đặc trưng và là yếu tố thúc đẩy cho loét tá tràng có nhiễm $\mathrm{H}$. pylori. Tuy nhiên, cần nghiên cứu trên số lượng nhiều hơn và sẽ cho kết quả khách quan hơn.,. 


\section{TÀI LIẸU THAM KHẢO}

1. Yamaoka $Y$. Mechanisms of disease: Helicobacter pylori virulence factors. Nat Rev Gastroenterol Hepatol. 2010;7(11): 629-641.

2. Yamaoka Y, Souchek J, Odenbreit S, et al. Discrimination between cases of duodenal ulcer and gastritis on the basis of putative virulence factors of Helicobacter pylori. Journal of clinical Microbiology 2002;40(6): 2244-2246

3. Khatoon J, Prasad KN, Prakash RR, et al. Association of heterogenicity of Helicobacter pylori cag pathogenicity island with peptic ulcer diseases and gastric cancer. Br. J. Biomed Sci 2017;74(3): 121-126

4. Liu J, He $C$, Chen $M$, et al. Association of presence/absence and on/off patterns of Helicobacter pylori oipA gene with peptic ulcer disease and gastric cancer risks: A meta-analysis. BMC Infectious Disease 20-13;13: 555-564

5. Braga LLBC, Batista MHR, de Azevedo OGR, et al. OipA "on" status of Helicobacter pylori is associated with gastric cancer in North-Eastern Brazil. BMC Cancer 2019;19(1):48

6. Lu $H$, Hsu $P$, Graham DY, Yamaoka $Y$. Duodenal ulcer promoting gene of Helicobacter pylori. Gastroenterology. 2005;128(4): 833-848.

7. Zhang Z, Zheng Q, Lu $\mathbf{H}$, et al. The Helicobacter pylori duodenal ulcer promoting gene, dupA, in China. BMC Gastroenterol. 2008; 8: 49-54.

8. Alam J, Sarkar A, Karmadar BC, et al. Novel virulence factor dupA of Helicobacter pylori as an important risk determinant for disease manifestion: An overview. World Journal of Gastroenterology 2020;26(32): 4739-4752

\section{HÀNH VI CỦA LÁI XE KHÁCH ĐƯờNG DÀI VÀ TAI NẠN GIAO THÔNG}

\section{TÓM TẮT}

Nghiên cứu được tiến hành nhằm tìm hiểu môt sỗ yếu tố hành vi của lái xe khách đường dài và mối liên quan với tai nan giao thông. 200 nam lái xe khách đường dài tuyển cố đinh liên tỉnh với tuổi đời trung bình là 40,9 45,6 tuổi và tuổi nghề trung bình là $12,4 \pm 5,6$ năm đã tham gia nghiên cứu. Các lái xe được phân tích đặc điểm công việc; điều tra, đánh giá hành vi theo thang DBQ (Driver Behaviour Questionnair có chỉnh sưaa) và hồi cứu số liệu tai nạn giao thông trong 3 năm liên tưc tai doanh nghiếp. Kết quả nghiên cứu cho thấy: Công việc của lái xe khách đường dài gây căng thẳng thần kinh tâm lý, thời gian lao động kéo dài, chế độ thay ca không ổn định, thường xuyên phải lái đêm, làm viêc trong tư thế bất lợi (phải ngồi lâu trong thời gian dài)... Các hành vi của lái xe: $52,5 \%$ mêt mỏi; $30,0 \%$ kiểm soát nguy co không tốt; $42,5 \%$ kém thư giãn; 44,5\% kém kiên nhẫn; 35,0\% lo lắng khi lái xe. Nguy cơ tai nan giao thông ở nhóm lái xe khách đường dài có biểu hiện trang thái mệt mỏi cao gấp 2,1 lần so với nhóm không có biểu hiện trạng thái mêt mỏi $(95 \% \mathrm{CI}=1,0-4,4)$; có điểm kiểm soát nguy cơ không tốt cao gấp 3,4 lần so với nhóm có điểm kiểm soát nguy cơ tốt $(95 \% \mathrm{CI}=1,6$ 7,2); điểm kiên nhẫn khi lái xe không tốt cao gấp 4,7 lần so với nhóm có điểm kiên nhẩn khi lái xe tốt $(95 \% \mathrm{CI}=2,0-11,3)$ với $\mathrm{p}<0.05 ; \mathrm{p}<0,01$ and $\mathrm{p}<0,001$. Các tác giả khuyến nghị cần áp dụng giải pháp kiểm soát hành vi lái xe góp phần giảm thiểu tai nạn giao thông.

Tư khoá: Hành vi, lái xe khách đường dài, tai nạn giao thông,

*Viên Sức khỏe nghề nghiêp và môi trường

Chịu trách nhiệm chính: Nguyễn Thu Hà

Email: thuhayhld@gmail.com

Ngày nhận bài: 3.6.2021

Ngày phản biên khoa hoc: 26.7.2021

Ngày duyệt bài: 3.8.2021
Nguyễn Thu Hà*, Nguyễn Đức Sơn*

\section{SUMMARY}

\section{BEHAVIOUR OF LONG DISTANCE DRIVER} AND TRAFFIC CCIDENTS

This study was carried out to to investigate some behaviour factors of long distance drivers and relationship with traffic accidents. 200 male drivers with $40.9 \pm 5.6$ years of age and $12.4 \pm 5.6$ participated in this study. The drivers are analyzed for job characteristics; investigating and evaluating sleep disorder according to Driver Behaviour Questionnair (DBQ) and retrospective traffic accident data for 3 years at the enterprise. The result showed that: The job characteristics of long distance drivers are high intensity of work; a working long time, unstable time; a night duty; a high responsibility, long sitting hours, ect... The driver's behavior: $52.5 \%$ were tired; $30.0 \%$ non-good risk control score; $42.5 \%$ less relaxed; $44.5 \%$ are impatient; $35.0 \%$ worry about driving. In the long-distance driver, the risk of traffic accidents of fatigue group was higher 2.1 times $(95 \% \mathrm{CI}=1.0$ 4.4); bad risk control score group was higher 3.4 times (95\% CI $=1.6-7.2)$; bad driving patience score group was higher 4.7 times $(95 \% \mathrm{CI}=2.0-11.3)$ than that among other group with $\mathrm{p}<0.05 ; 0.01$ and 0.001 . The author recommended that it is necessary to control behaviour of drivers to help reduce traffic accidents.

Keywords: Behaviour, long distance drivers, traffic accident

\section{I. ĐĂT VẤN ĐỀ}

Hành vi của lái xe (sử dụng điên thoai di đông, thiếu kiên nhẫn, kiểm soát nguy cơ không tốt, mệt mỏi...) và an toàn giao thông có mối liên quan với nhau. Khi lái xe bị phân tâm bởi điện thoại di động có thể làm thay đổi tốc độ lái xe dẫn đến mâu thuẫn với người tham gia giao thông (kiểm soát nguy cơ không tốt) và do đó tăng nguy cơ tai nạn. 